\title{
The Bath Philosophical Society and its influence on William Herschel's Career
}

\section{Francis Ring}

\begin{abstract}
At a time when eighteenth-century Bath was rapidly expanding, new buildings and an influx of people made it one of the most popular places outside London. The city became a centre for fashion, music, learning, and architecture on a new scale. It became a centre also for discussion on current affairs, since newspapers were not freely available. Some were fascinated by science though few had a chance to study the new interests of the time. There were travelling teachers who made money by going around the country to give illustrated talks on scientific subjects. It is said that the private hiring of such people was an influential and entertaining way of reaching your friends and contacts. One such was Dr Desagulier, who ran a course on Experimental Philosophy in Bath. His course included optics and he used a Planetarium to demonstrate the motions of the heavenly bodies.
\end{abstract}

In the second half of the eighteenth century an Agricultural Society had formed to help badly organised farmers improve the much-needed harvests. From this a smaller group agreed to form The Bath Philosophical Society to concentrate on physics and science, which were already becoming a fashionable hobby for the rich as well as for intellectuals of the time. Twenty-seven people were invited to join this limited membership, of which William Herschel was one, and Joseph Priestly was another. Through regular meetings, often two per week, Herschel became an active member and had an opportunity to publicise his astronomical observations and ideas. Later, after Herschel left Bath, the Society collapsed and unfortunately no records have survived. There are, however, some notes included in the archive of Herschel's papers published by the Royal Astronomical Society in two large volumes. Many of the papers given first in Bath were subsequently presented in London, and published in the Philosophical Transactions of The Royal Society, London.

Herschel, the German Musician who came to Bath in order to fulfil his life as a composer, musician and teacher, left the city as a ground-breaking amateur Astronomer, later to become one of the World

Francis Ring, 'The Bath Philosophical Society and its influence on William Herschel's career', eds. Nicholas Campion and Rolf Sinclair, Culture and Cosmos, Vol. 16 nos. 1 and 2, 2012, pp. 45-52.

www.CultureAndCosmos.org 
46 The Bath Philosophical Society and its Influence on William Herschel's Career

leaders in that subject. Undoubtedly, the local Society played a part in the rapid development of this musician-turned-scientist of special renown.

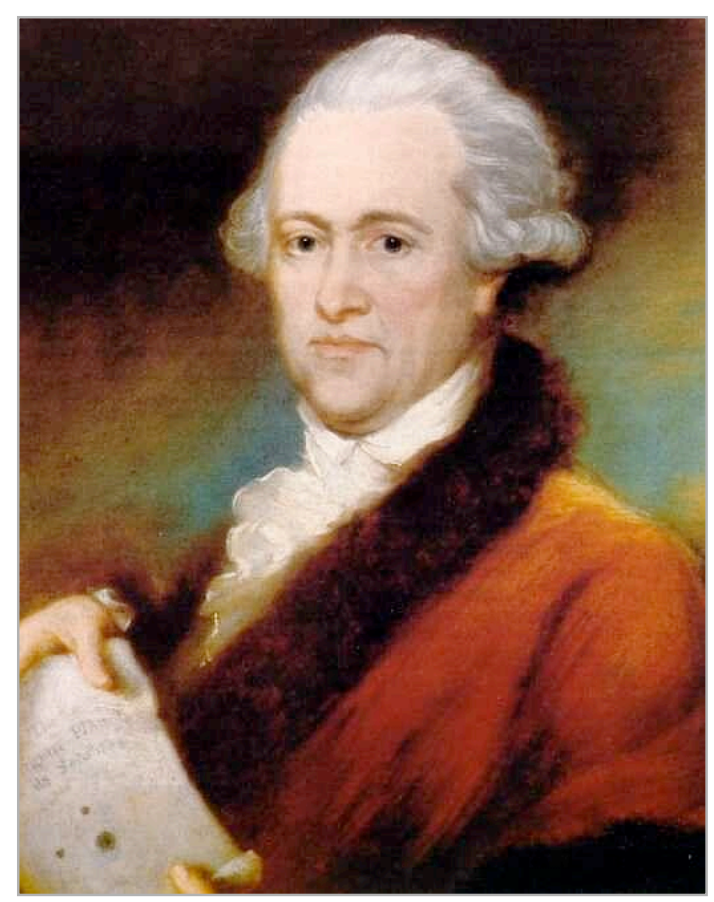

Figure 1. Sir William Herschel, The Herschel Museum of Astronomy, Bath $^{1}$

In the early eighteenth century Bath was a small spa. However, within a few years there was rapid growth, with new buildings constantly under construction, using the local Bath stone. An especially important architect, John Wood, developed a style based on classical architecture from Italy and used this grand style to build crescents of individual houses on a new and majestic scale. At this time there was a significant influx of people, making it one of the most popular small cities outside London. As a result the city became a centre for fashion, music, learning, and architecture. It became a focus also for discussion on current affairs,

${ }^{1}$ From T. Fawcett, 'Science Lecturing in Georgian Bath', in P. Wallis, ed., Innovation \& Discovery: the rise of science (Bath: BRLSI \& William Herschel Society, 2008).

Culture and Cosmos 
since newspapers were not freely available. Some were fascinated by science though few had a chance to study the new interests of the time. ${ }^{2}$

There were travelling teachers who made money by going around the country to give illustrated talks on scientific subjects. It is said that the private hiring of such people was an influential and entertaining way of reaching your friends and contacts. In 1737 Dr Desagulier ran a course on Experimental Philosophy in Bath. He announced in the local newspaper that his experiments would demonstrate the principles of mechanics, hydrostatics and optics. His course could be attended for the sum of three guineas, which was payable through Mr Leake's bookshop. It included the exciting device known as a Planetarium to demonstrate the motions, magnitude and distances of the heavenly bodies, in ways that had never before been shown. His skill must have been well demonstrated by his proud announcement that he had built a clockwork instrument to show the phenomena of the tides. Sadly, there are no surviving details of this device today. However, the Planetarium became a popular science toy at that time, many of which have survived.

The popular concept was that new knowledge was a tangible way to improve society and therefore be a force for good in the world. These public lectures were pitched to attract both men and women, and were a highlight of the season of the year when visitors would be in Bath. Other itinerant teachers came to Bath, including Benjamin Martin of Chichester, who had also built some of his own instruments. In 1743 he advertised his orrery to explain the solar system, a 'cometarium', a celestial globe, a reflecting telescope and a very precise baroscope. Martin claimed that his syllabus was 'not for amusement only, but intended as a science to exhibit a just idea of the true nature, reason and state of things, as far as they be known'. Part of Martin's display was the Leyden jar, to show the capacitor that could discharge to order. This, of course, became an appealing topic for travelling showmen, who used the electrical phenomena to deliver shocks or produce a shower of sparks for public amusement. Martin, facing criticism and accusations of being a mercenary, established himself in London to sell scientific instruments.

\footnotetext{
${ }^{2}$ For what follows see Constance Lubbock, The Herschel Chronicle (Bath: William Herschel Society, reprint 2010); Michael Hoskin, The Herschel Partnership (Cambridge: Science History Publications, 2003); Michael Hoskin, The Herschels of Hanover (Cambridge: Science History Publications, 2007); Peter Wallis, ed., Innovation and Discovery: the rise of science in Bath (Bath: Bath Royal Literary and Scientific Institution: William Herschel Society, 2011).

${ }^{3}$ Fawcett, 'Science Lecturing', Chapter 11.
} 
48 The Bath Philosophical Society and its Influence on William Herschel's Career

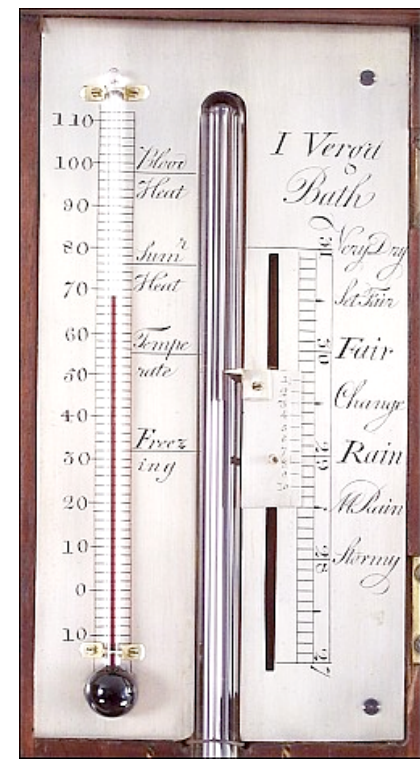

Figure 2. A thermometer and barometer made in Bath in the $18^{\text {th }}$ Century, The Herschel Museum of Astronomy, Bath ${ }^{4}$

As the interest in travelling education grew in Bath and many other towns across the country, so the number of teachers and audiences increased. James Ferguson FRS came to Bath in 1766, his visit arranged by a local bookseller who was selling a reissue of 'Lectures in Mechanics and Astronomy Explained'. His astronomy short courses proved to be the most popular of his subjects. In 1744, when he was sixty-four years old, he gave a series of twelve lectures, which it is thought could have had a part in stimulating the musician William Herschel to become involved with the subject.

By the second half of the eighteenth century an Agricultural Society had formed to help badly organised farmers improve the muchneeded harvests. From this a smaller group agreed to form The Bath Philosophical Society to concentrate on natural philosophy (physics and science), already a fashionable hobby for the rich or intellectuals of the time. It was a select group of twenty-seven people who were invited to join this limited membership. William Herschel was one and Joseph Priestly was another, both of whom remain pioneers in the history of science.

${ }^{4}$ W.J. Williams and D.M. Stoddart, Bath - Some Encounters with Science (Bath: Kingsmead Press, 1978), p. 70.

Culture and Cosmos 
The secretary, Edmund Rack, proudly announced that 'this Institution promises much rational improvement and instruction: and has a more favourable beginning than the Royal Society in London had 100 years ago - there being only five members for more than two years, and those five not superior in learning and genius to most of our members'. ${ }^{5}$ The other members were in fact an odd assortment, although medical doctors and men of the church were among the better educated. It seems likely that a number of the Society members contributed little beyond providing an audience for the few. We do know that William Smith, later famous for his geological maps, started out by studying the environs of Bath, whilst surveying for coal mines and quarries in the area.

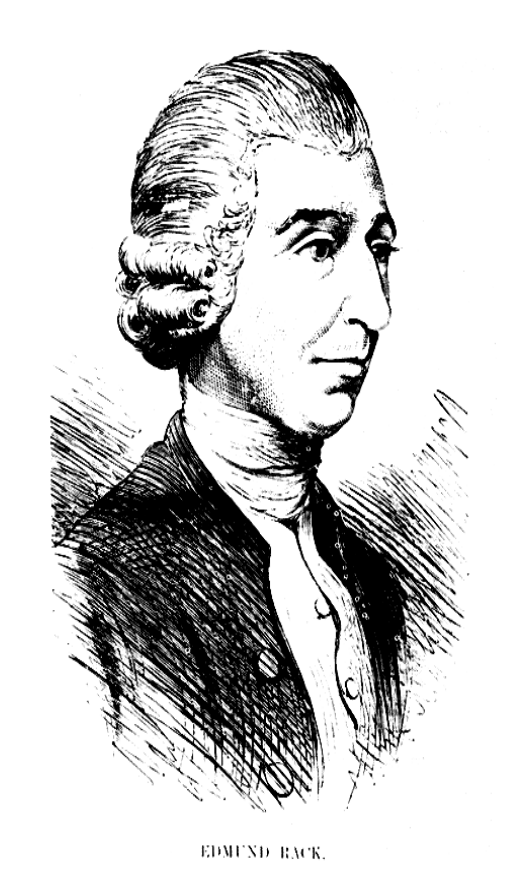

Figure 4. Portrait of Edmund Rack ${ }^{6}$

Another more active member was John Arden, an educator offering a course in natural and experimental philosophy from his house in St James Street, costing just one guinea for twenty lectures! He promised to make his lectures plain and intelligible. He also gave private lessons to young

\footnotetext{
${ }^{5}$ W.J. Williams and D.M. Stoddart, Bath - Some Encounters with Science (Bath: Kingsmead Press, 1978), p. 70.

${ }^{6}$ in Anon., 'Philosophical Societies to BRLSI', The Bath Royal Scientific and Literary Institution, http://www.brlsi.org/node/18149.
} 
50 The Bath Philosophical Society and its Influence on William Herschel's Career

people on elementary astronomy and geography, something he continued in 1769 and 1770. Before long local rivalry and clashes of the meetings meant that the urge to outdo the competition must have flourished!

It is known that a number of science meetings took place in private around Bath; the local newspaper recorded that John Bryant, esquire, hosted such a demonstration with his electrical machine by himself, Arden, and Herschel, even the lighting of candles by electrical sparks! Bryant, in fact, was a local draper and soap manufacturer. But he was also described as 'electrician and astronomer'.

Bryant's electrical machine that he put at the disposal of the Bath Philosophical Society would today have a value of $£ 7,500$. He built a telescope with help from William Herschel, and seems to have slowly expanded his business into optical instruments. It is on record that William Herschel first hired a telescope in 1773. This was from a Bath shop that primarily sold silver plate, surgeon's knives and clocks. Such premises, responding to local demand, progressively turned to the hiring of barometers and an assortment of optical instruments. The fascination with electricity even led to courses of shock treatment by this same shop strictly for 'medical purposes!'

Through regular meetings of the Society, often two per week, Herschel became an active member and had an opportunity to publicise his astronomical observations and ideas. His famous discovery on 13 March 1781 of Uranus, made with his home-made seven-foot telescope, would have been immediately communicated to the close circle of which William Watson was one. It was Watson who brought Herschel to the attention of George III, and from then on, everything began to change. Herschel's fame grew and he became a fellow of The Royal Society, and of course moved from Bath to be near The Palace of Windsor and to become King's Astronomer.

During the three years that Herschel was a member, until his departure in 1781, he gave thirty-one presentations. It was also reported that William Herschel chose the name Georgium Sidus for the new planet after discussion with his friends at Bath. The name, however, did not survive, though there are a few surviving celestial globes bearing that name, before Uranus was ultimately adopted. Later, after Herschel left Bath, the Society collapsed and unfortunately no records have survived. There are however, some notes included in the archive of Herschel's papers published by the Royal Astronomical Society in two large volumes. Many of the papers given first in Bath were subsequently 
presented in London, and published in the Philosophical Transactions of The Royal Society, London.

Herschel, who came to Bath, to fulfil his life as a composer, musician and teacher, left the city as a ground breaking amateur astronomer, later to become one of the world leaders in that subject. Undoubtedly, the Bath Philosophical Society provided him with a critical opportunity to develop the art of scientific presentation. Bath proved to be a fertile place for the quest for discovery at a time when enthusiastic amateurs and curiosity linked to entertainment made a local society viable. The eclectic grouping of such people was possible outside the classical university setting at this time in history. The emerging social society in Bath played a definite part in the rapid development of this musician-turned-scientist of special renown.

After leaving Bath, William married the widow of a friend he made at Slough, and this changed his financial circumstances. Their only son, John, grew up in a different situation, with greater opportunities for education, and became a scholar at Cambridge.

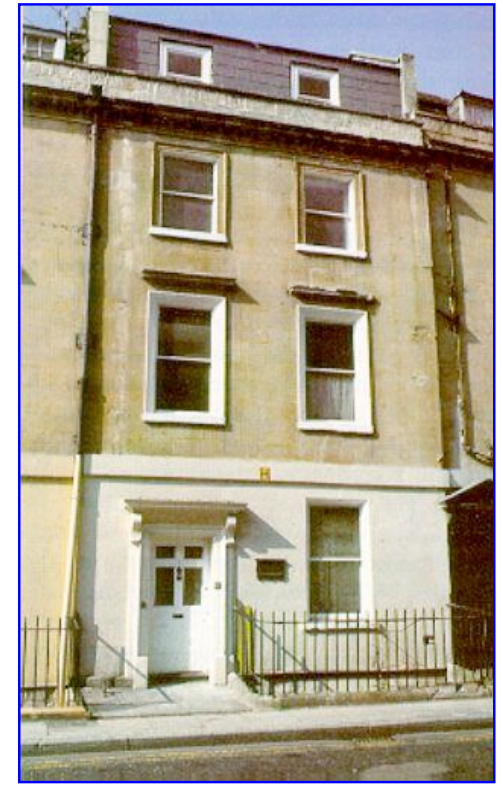

Figure 5. The Herschel Museum of Astronomy, Bath

The Herschel Museum of Astronomy in New King Street, Bath, is a modern tribute to the talented Herschel Family. It is the last surviving 
52 The Bath Philosophical Society and its Influence on William Herschel's Career

house in which William, Caroline his sister, and Alexander his brother lived in the late eighteenth Century.

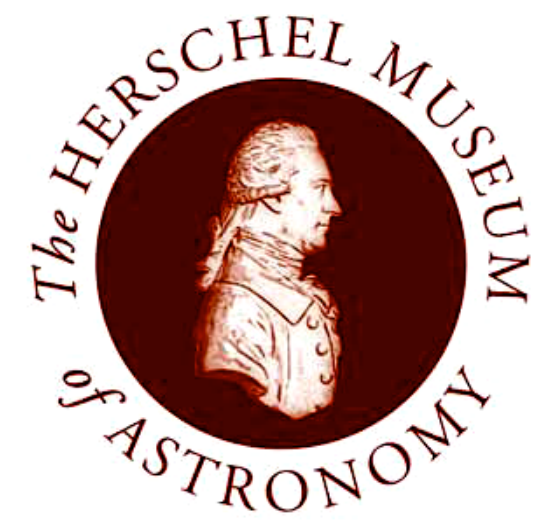

Figure 6. The Herschel Museum of Astronomy, Bath 